Research Paper

\title{
The Statistical Study on the Effects of Physicochemical Properties of Soil on Single Extraction Methods for Heavy Metals
}

\author{
Hyeop-Jo Han, Chang-Woo Song, Jong-Un Lee* \\ Department of Energy and Resources Engineering, Chonnam National University, Gwangju 61186, Korea \\ *Corresponding author : jongun@jnu.ac.kr
}

\section{ARTICLE INFORMATION}

Manuscript received 24 March 2021

Received in revised form 8 April 2021

Manuscript accepted 9 April 2021

Available online 28 April 2021

DOI : http://dx.doi.org/10.9719/EEG.2021.54.2.259

\section{Research Highlights}

- Correlation and multiple regression analysis were applied for soils with different physicochemical properties.

- Physicochemical properties of soil explain up to $74 \%$ of variances of single extraction results.

- Physicochemical properties of soil influence on heavy metal concentrations leached by single extraction methods.

\begin{abstract}
The effects of the physicochemical properties of soil such as soil pH, cation exchange capacity, and organic matter content on single extraction of $\mathrm{Cd}, \mathrm{Cr}, \mathrm{Cu}, \mathrm{Ni}, \mathrm{Pb}$, and $\mathrm{Zn}$ using $\mathrm{CaCl}_{2}, \mathrm{HOAc} \mathrm{HNO}_{3}$, and DTPA were statistically investigated for 69 agricultural soils in Korea. Correlation analysis and multiple regression analysis were applied for soil samples which were grouped on the basis of average values of the physicochemical properties of the soil. Diluted $\mathrm{HNO}_{3}$ extracted higher concentrations of $\mathrm{Cr}, \mathrm{Cu}, \mathrm{Ni}$, and $\mathrm{Pb}$ when compared with the other extractants, however, similar amounts of $\mathrm{Cd}$ and $\mathrm{Zn}$ were extracted by $\mathrm{HOAc}$ with $\mathrm{HNO}_{3}$. The results of correlation analysis indicated that DTPA extraction showed a high correlation with other single and pseudo-total extraction methods, and the physicochemical properties of soil influenced the concentrations of heavy metals leached by the single extraction methods. In the case of $\mathrm{Zn}$, high correlations between pseudo-total and the studied single extraction methods were observed. As a result of regression analysis, it was found that the physicochemical properties of the soil could explain up to $74 \%$ of variances of the single extraction results. These results indicate that the physicochemical properties of the soil can have a direct influence on the concentrations of heavy metals extracted by the single extraction methods.
\end{abstract}

Keywords : soil, heavy metal, single extraction, correlation, regression analysis

Citation: Han, H.-J., Song, C.-W., Lee, J.-U. (2021) The Statistical Study on the Effects of Physicochemical Properties of Soil on Single Extraction Methods for Heavy Metals. Korea Economic and Environmental Geology, v.54, p.259-269, doi:10.9719/ EEG2021.54.2.259. 


\title{
연구논문
}

\section{토양의 물리화학적 특성이 중금속 단일용출법에 미치는 영향에 대한 통계학적 연구}

\author{
한협조 - 송창우 · 이종운 ${ }^{*}$ \\ 전남대학교 에너지자원공학과 \\ *책임저자 : jongun@jnu.ac.kr
}

\section{요 약}

국내 69개 농경지 토양 내 $\mathrm{Cd}, \mathrm{Cr}, \mathrm{Cu}, \mathrm{Ni}, \mathrm{Pb}, \mathrm{Zn}$ 을 대상으로 하여 토양 $\mathrm{pH}$, 양이온교환능력, 유기물 함량 등의 물리화학적 특 성이 $\mathrm{CaCl}_{2}, \mathrm{HOAc}, \mathrm{HNO}_{3}, \mathrm{DTPA}$ 등을 이용한 중금속의 단일용출 결과에 미치는 영향을 통계학적으로 조사하였다. 통계학적 분석은 토양의 물리화학적 특성의 평균값을 기준으로 높고 낮은 두 표본으로 구분한 후 이에 대해 상관분석과 다중회귀분석을 수행하였다. $\mathrm{Cr}, \mathrm{Cu}, \mathrm{Ni}, \mathrm{Pb}$ 의 경우 $\mathrm{HNO}_{3}$ 를 적용하였을 때 다른 추출제에 비하여 높은 함량이 추출되었으나, $\mathrm{Cd}, \mathrm{Zn}$ 의 경우 $\mathrm{HOAc}$ 를 이용한 추출에서도 유사한 함량이 추출되었다. 상관관계 조사 결과, DTPA 추출이 다른 단일용출 및 전함량과 상관관 계가 높았으며, 토양의 물리화학적 특성이 단일용출 결과에 영향을 미치는 것으로 나타났다. $\mathrm{Zn}$ 의 경우, 전함량과 모든 단일용 출법들에 의한 추출 함량이 상호 높은 상관관계를 보였다. 회귀분석 결과, 토양의 물리화학적 특성은 최대 $74 \%$ 에 이르는 단일 용출 결과의 분산을 설명할 수 있는 것으로 나타났다. 이러한 결과는 토양의 물리화학적 특성이 단일용출 결과에 직접적인 영 향을 미칠 수 있음을 나타낸다.

주요어 : 토양, 중금속, 단일용출, 상관관계, 회귀분석

\section{1. 서 론}

우리나라는 중금속에 의한 토양 오염을 판단하기 위해 토양을 강한 혼합산인 왕수(aqua regia)로 침출한 후 침 출액 내 중금속 함량을 측정하는 전함량(pseudo-total) 개 념의 방식을 사용한다. 반면 외국의 경우, 독일은 $\mathrm{NH}_{4} \mathrm{NO}_{3}$ (DIN, 1997), 스위스는 $\mathrm{NaNO}_{3}(\mathrm{VSBo}, 1986)$ 를 사 용하는 등 약한 추출제를 이용하여 중금속에 의한 토양 위해성을 판단하기도 한다(Han et al., 2020).

중금속은 토양 내에서 다양한 결합 형태, 예를 들면 이 온교환성, 탄산염 결합, 철·망간산화물 결합, 유기물 결합, 황화물, 잔류상 등으로 존재하며(Tessier et al., 1979; Zimmerman and Weindorf, 2010), 환경 변화에 의한 중 금속의 이동도(mobility) 및 생물이용도(bioavailability)는 이러한 중금속의 결합 형태에 크게 의존한다. 특히 농작 물을 재배하는 농경지 토양의 경우, 인체 내로 직접 흡 수된다는 특수성으로 인하여 토양으로부터 작물로 용이 하게 전이될 수 있는 식물유효태(phytoavailable) 중금속 의 함량이 중요하다(Heemsbergen et al., 2009; Salazar et al., 2012). 왕수 등의 혼합강산으로 추출된 토양 내 고농 도의 중금속 함량이 그대로 작물로 전이될 것으로 예측 하기는 어렵다(Krishnamurti and Naidu, 2003; Meers et al., 2007a,b).

그간 토양 내 유효태 중금속 함량을 측정하기 위한 다 양한 '단일 또는 혼합용출법'이 많이 개발되었다. (이 논 문에서는 이들을 왕수에 의한 중금속의 전함량 추출과 대비하여 모두 '단일용출법'이란 용어로 통칭하도록 한 다) 널리 사용되는 추출제로는 $0.01 \mathrm{M} \mathrm{CaCl}_{2}, 0.1 \mathrm{M}$ $\mathrm{NaNO}_{3}, 1 \mathrm{M} \mathrm{NH}_{4} \mathrm{NO}_{3}$ 등 무기염 추출제, $0.11 \mathrm{M} \mathrm{HOAc}$, $1 \mathrm{M} \mathrm{NH}_{4} \mathrm{OAc}$ 등 유기산 추출제, $0.1 \mathrm{M} \mathrm{HNO}_{3}, 0.1 \mathrm{M}$ $\mathrm{HCl}$ 등 무기산 추출제, $\mathrm{EDTA}$ (ethylenediaminetetraacetic acid)- $\mathrm{NH}_{4} \mathrm{OAc}$, DTPA(diethylenetetraminepentaacetic acid)$\mathrm{CaCl}_{2}$, Mehlich 3 등 혼합추출제 등을 들 수 있다(Meers et al., 2007a; Seo et al., 2013; Han et al., 2020). 이러한 추출제들은 대체로 왕수에 비하여 중금속 용출 정도가 약하고, 적용 과정이 안전하며 간편하다. 단일용출법에 관한 그간의 국내외 연구는 주로 용출법 간의 통계학적 분석 또는 식물 전이 함량과 단일용출 함량 간의 상관관 계 분석 등이 주를 이룬다(Meers et al., 2007a,b; Seo et al., 2013; Lim et al., 2014; Kelepertzis et al., 2015; Chiou and Hsu, 2019).

복수의 토양을 왕수로 침출한 결과 중금속 전함량이 유 사하게 나온 경우라 하더라도, 이들 토양에 동일한 단일 용출법을 적용하였을 때 역시 유사한 결과가 나오리라고 
예상하기는 어렵다. 이는 단일용출법으로 추출되는 토양 내 중금속의 거동은 토양의 다양한 물리화학적 특성, 예 를 들면 토양 $\mathrm{pH}$, 양이온교환능력(cation exchange capacity, 이하 CEC), 유기물함량(organic matters content, 이하 OM) 등에 의해 좌우될 수 있기 때문이다.

이와 관련하여, 산성토에서의 중금속 용출특성을 확인 하는 연구는 수행된 바 있으나(Zhu et al., 2012), 중성 및 염기성 토양에 대한 연구는 수행되지 않았다. 또한 토양 을 입도별로 구분하여 사토(sandy soil) 및 점토(clayey soil)에서 중금속의 용출특성을 비교한 연구가 수행된 바 있지만 EDTA 용출법에 의해 추출된 중금속의 용출특성 에 대해서만 연구가 이뤄졌다(Lo and Yang, 1999). $\mathrm{pH}$ 와 입도를 함께 고려하여 여러 단일용출법의 중금속 용출특 성을 비교한 연구가 수행된 적도 있으나(Meers et al., 2007a), 이 연구에서는 오직 $\mathrm{Cd}$ 의 용출특성만을 확인하 였다. 대체적으로 지금까지의 단일용출법에 관한 연구는 토양의 $\mathrm{pH}, \mathrm{CEC}, \mathrm{OM}$ 등 다양한 물리화학적 특성에 관 한 고려가 거의 없는 상태에서 수행되었을 뿐만 아니라 여러 중금속과 단일용출법에 대한 통합적인 분석은 이뤄 진 바 없다.

이 연구에서는 국내의 69 개 농경지 토양을 채취하여 토양 $\mathrm{pH}, \mathrm{CEC}, \mathrm{OM}$ 을 측정하고, 왕수 추출을 통한 중금 속 $(\mathrm{Cd}, \mathrm{Cr}, \mathrm{Cu}, \mathrm{Ni}, \mathrm{Pb}, \mathrm{Zn})$ 전함량을 정량하였다. 또한 동일한 시료에 대하여 $0.01 \mathrm{M} \mathrm{CaCl}_{2}$ (무기염), $0.11 \mathrm{M}$ $\mathrm{HOAc}$ (유기산), $0.5 \mathrm{M} \mathrm{HNO}_{3}$ (무기산), 0.005 M DTPA + $0.01 \mathrm{M} \mathrm{CaCl}_{2}+0.1 \mathrm{M} \mathrm{TEA}$ (triethanolamine)(혼합추출제, 이하 DTPA로 통칭) 등 추출제 종류별 단일용출법을 적 용하여 용출된 각 중금속 함량을 측정하였다. 토양 내 중 금속 정량의 결과를 바탕으로 통계학적 분석을 진행하여, 1) $\mathrm{pH}, \mathrm{CEC}, \mathrm{OM}$ 별로 분류한 각 표본에서 전함량 분석 법과 단일용출법 간의 상관분석, 2) 단일용출법에 의해 용출되는 중금속 함량과 토양 내 존재하는 중금속의 전 함량 및 토양의 물리화학적 특성 간의 상호 관련성 분석 을 수행하였다. 이를 위해 토양을 (1) 전체 토양 및 (2) $\mathrm{pH}, \mathrm{CEC}, \mathrm{OM}$ 의 평균을 기준으로 하여 높은 토양과 (3) 낮은 토양 등 총 세 그룹으로 나눈 후 각 그룹 내에서 중 금속의 전함량과 단일용출 함량들 간의 상관관계를 구하 였다. 또한 각 그룹별로 단일용출 함량을 종속변수, $\mathrm{pH}$, $\mathrm{CEC}, \mathrm{OM}$ 및 왕수에 의한 전함량을 독립변수로 하여 다 중회귀분석을 수행함으로써 토양의 물리화학적 특성 및 전함량과 단일용출법 간의 상호관계를 확인하고자 하였다.

기존의 연구에서 전함량과 단일용출에 의해 추출된 함 량 간의 상관분석(Zhu et al., 2012; Lima et al., 2016), 토양의 물리화학적 특성과 단일용출간의 상관분석 및 회 귀분석(Meers et al., 2007a; Seo et al., 2013; Sungur et al., 2014), 토양의 물리화학적 특성과 단일용출에 의해 추출된 중금속 함량으로 식물로 전이된 중금속 함량을 예측하는 회귀분석(Zhang et al., 2010) 등의 연구가 수행 된 바 있으나, 토양을 $\mathrm{pH}, \mathrm{CEC}, \mathrm{OM}$ 등 물리화학적 특 성에 의해 구분하여 많은 중금속의 다양한 단일용출 함 량에 대한 통계학적 분석을 수행하려 한 것은 처음 시도 되는 것이다.

통계학적 유의성(significance)을 확보한 상태에서 토양 을 물리화학적 조건에 따라 구분하여 세밀하게 수행한 이 연구의 결과가 최근 실용적 관심의 대상이 되고 있는 오염 농경지 토양의 단일용출법과 관련된 후속 연구에 중요한 정보를 제공할 수 있을 것으로 기대하였다.

\section{2. 실험방법}

\section{1. 토양시료 채취}

연구 대상 시료는 국내 화력발전소 주변 약 $3.5 \mathrm{~km}$ 이 내의 농경지 토양을 선택하였다. 이를 위해 경남 삼천포 및 하동 화력발전소 주변에서 각각 11 개, 9 개, 충남 서천, 보령, 태안 화력발전소 주변에서 각각 10 개씩, 강원 영동 및 동해 화력발전소 주변에서 각각 10 개, 8 개의 토양 시 료를 채취하였다. 각 화력발전소를 중심으로 $1 \mathrm{~km}$ 단위 의 정사각형 격자를 구성한 뒤 각 격자 내에 존재하는 농경지 토양에서 표토와 심토를 채취하였다. 시료 대부 분은 표토이며 심토는 전체 69 개 시료 중 14 개이다. 표 토는 표면의 유기물을 제거하고 스테인리스 스틸 삽으로 채취하였으며, 심토는 핸드 오거를 이용하여 $40 \sim 50 \mathrm{~cm}$ 심부의 토양을 채취하였다.

\section{2. 토양의 물리·화학적 분석}

채취한 시료는 불순물을 육안으로 선별, 제거하고 직 사광선이 없는 곳에서 자연건조한 후, 토양의 물리화학 적 특성을 파악하기 위하여 토양 $\mathrm{pH}, \mathrm{CEC}$, 작열감량 $(\mathrm{LOI}$; loss-on-ignition)을 측정하였다(Song et al., 2019). 측정된 작열감량을 이용하여 Eq. 1 3을 이용, $\mathrm{OM}$ 을 추정하였다 (Boyle, 2004).

$$
\operatorname{LOI}(\%)=\frac{\left(\mathrm{T}_{\mathrm{a}}-\mathrm{T}_{\mathrm{b}}\right)}{\left(\mathrm{T}_{\mathrm{a}}-\mathrm{T}_{\mathrm{c}}\right)} \times 100
$$

Organic carbon $=0.458 \times$ LOI -0.4

Organic matter $=$ organic carbon $\times 1.724$

(Eq. 3)

이때, $\mathrm{LOI}$ 는 작열감량, $\mathrm{T}_{\mathrm{a}}$ 는 $105{ }^{\circ} \mathrm{C}$ 에서 1 시간 가열 후 무게, $\mathrm{T}_{\mathrm{b}}$ 는 $550{ }^{\circ} \mathrm{C}$ 에서 6 시간 가열 후 무게, $\mathrm{T}_{\mathrm{c}}$ 는 회화용 
기의 무게이다.

$-80 \mathrm{mesh}$ 토양을 $15 \mathrm{~mL}$ 코니칼 튜브에 $1 \mathrm{~g}$ 정량 후 왕수를 넣고 $70{ }^{\circ} \mathrm{C}$ 에서 2 시간 가열하여 토양 내 $\mathrm{Cd}, \mathrm{Cr}$, $\mathrm{Cu}, \mathrm{Ni}, \mathrm{Pb}, \mathrm{Zn}$ 을 추출한 후 ICP-OES(Spectro Genesis, Spectro, Germany)를 이용하여 전함량을 정량하였다. 이때 왕수분해한 중금속 분석의 신뢰성을 확인하기 위하여 ISO 인증표준물질인 BAM-U110(CRM BAM-U110, BundesAnstalt für Materialforschung, Germany)을 삽입하여 분석한 후 IBM SPSS Statistics 26 프로그램의 일표본 $\mathrm{t}$ 검정을 이 용하여 정확도를 측정한 결과 $(p<0.05)$, 모든 중금속이 표준물질의 불확실성(uncertainty) 범위 내에서 통계적으 로 유의한 정확도를 보임을 확인하였다.

$0.01 \mathrm{M} \mathrm{CaCl}_{2}$ (pH 5.5) 용출은 -10 mesh 건조 토양 $2 \mathrm{~g}$ 에 추출제 $20 \mathrm{~mL}$ 을 주입한 후 $20{ }^{\circ} \mathrm{C}$ 에서 $50 \mathrm{rpm}$ 으로 2 시간 동안 반응시켰다(Houba et al., 2000). 반응 후 원심 분리 $(2,000 \mathrm{rpm}, 5$ 분 $)$ 와 $0.45 \mu \mathrm{m}$ 여과를 통하여 콜로이 드를 제거하였다. 0.11 M HOAc (pH 2.8) 용출은 -10 mesh 건조 토양 $1 \mathrm{~g}$ 에 추출제 $40 \mathrm{~mL}$ 을 넣은 후 $22{ }^{\circ} \mathrm{C}$ 에서 16 시간 반응시켰다. 추출액을 $3,000 \mathrm{rpm}$ 에서 20 분간 원심 분리한 후 상등액을 취하였다(Rauret et al., 1999). 0.5 M $\mathrm{HNO}_{3}$ (pH 1.0 이하) 용출은 건조 토양 $2 \mathrm{~g}$ 에 추출제 $10 \mathrm{~mL}$ 을 주입한 후 $20{ }^{\circ} \mathrm{C}$ 에서 $120 \mathrm{rpm}$ 으로 2 시간 동안 반응 시켰다(van Ranst et al., 1999). DTPA (pH 7.3) 용출액은 $0.005 \mathrm{M} \mathrm{DTPA}, 0.01 \mathrm{M} \mathrm{CaCl}_{2}, 0.1 \mathrm{M} \mathrm{TEA}$ 를 주입한 후 $\mathrm{HCl}$ 을 이용하여 $\mathrm{pH}$ 를 조정하였다(Lindsay and Norvell, 1978). -10 mesh 건조 토양 $2 \mathrm{~g}$ 에 DTPA 용출액 $4 \mathrm{~mL}$ 을 주입한 후 뚜껑을 막고 $20{ }^{\circ} \mathrm{C}, 120 \mathrm{rpm}$ 으로 2시간 동안 반응시켰다. 원소 정량은 ICP-OES(Spectro Genesis, Spectro, Germany)를 이용하였다.

\section{3. 통계학적 분석}

모든 통계학적 분석은 SPSS(IBM SPSS Statistics 26) 를 이용하여 수행하였다. 이때 데이터의 정규분포 여부 를 확인한 후 양의 왜도(positive skewness)를 보이는 데 이터는 대수 $(\log )$ 로 변환시켜 투입하였다. 토양의 물리화 학적 특성별 중금속 거동을 알아보기 위하여 $\mathrm{pH}, \mathrm{CEC}$, $\mathrm{OM}$ 의 평균값을 기준으로 각각 낮은 토양과 높은 토양으 로 구분하여 통계학적 분석을 수행하였으며 이들을 통합 한 전체 토양에 대해서도 분석을 하였다.

다중회귀분석의 경우, $\mathrm{Cd}, \mathrm{Cr}, \mathrm{Cu}, \mathrm{Ni}, \mathrm{Pb}, \mathrm{Zn}$ 에 대하 여 종속변수는 각 단일용출 추출값, 독립변수는 토양 $\mathrm{pH}$, $\mathrm{CEC}, \mathrm{OM}$, 왕수분해를 통한 전함량 분석값으로 하였다. 이때 독립변수 투입방식은 모든 독립변수를 동시에 포함 하여 분석하는 동시입력 회귀분석(enter regression)과 종 속변수에 대한 설명력이 높은 일부 독립변수만 포함한
단계입력 회귀분석(stepwise regression) 두 가지로 수행 하여 결과를 비교하였다.

\section{3. 결과 및 해석}

\section{1. 토양의 물리·화학적 분석}

연구 대상인 총 69개 토양의 물리·화학적 특성을 분석 한 결과, $\mathrm{pH}$ 는 4.8 8.6 범위로서 평균 6.5 , 표준편차 0.9, $\mathrm{CEC}$ (단위: $\mathrm{meq} / 100 \mathrm{~g}$ )는 6.0 40.2 범위로서 평균 20.0, 표준편차 $7.4, \mathrm{OM}$ 은 $1.0 \sim 15.0(\%)$ 범위로서 평균 $4.2 \%$, 표준편차 $2.6 \%$ 였다(Table 1). 연구 대상 토양의 $\mathrm{pH}$ 는 국 내 농경지 평균 $\mathrm{pH} 6.2$ 및 4.5 8.4(MOE, 2020) 범위와 매우 유사하며, $\mathrm{CEC}$ 와 $\mathrm{OM}$ 은 국내 농경지 평균값인 10.0 $\mathrm{meq} / 100 \mathrm{~g}(\mathrm{Kim}$ et al., 2009)과 2.3\%(Roh et al., 2015)에 비해 다소 높았다.

\section{2. 중금속 함량}

왕수와 각 단일용출법으로 추출한 원소의 함량은 Table 1 에 나타내었으며, 각 단일용출법으로 추출한 중금속 함 량의 비교를 Fig. 1에 도시하였다. Fig. 1의 상자수염그림 (box-and-whisker diagram)에서 상자는 제 1 3사분위수, 상 자 내의 가로선은 중앙값, $\times$ 는 평균값을 의미한다. 상자 바깥의 상하 가로선은 중앙값에서 1.5 배만큼의 사분범위 (interquartile range)를 초과한 값 중 중앙값에 가까운 값 을 기준으로 상하에 각각 나타냈었으며, 이를 벗어난 값 은 동그란 점으로 표시하였다.

$\mathrm{Cr}, \mathrm{Cu}, \mathrm{Ni}, \mathrm{Pb}$ 의 경우 무기산 추출제인 $0.5 \mathrm{M} \mathrm{HNO}_{3}$ (이 하 각 추출제 앞의 농도 미기재)를 적용하였을 때 다른 추출제에 비하여 높은 함량이 추출되었으며, 혼합추출제 인 DTPA가 뒤이어 상대적으로 높은 추출효과를 보였다 (Fig. 1). 한편 $\mathrm{Cd}$ 와 $\mathrm{Zn}$ 의 경우 유기산 추출제인 $\mathrm{HOAc}$ 가 $\mathrm{HNO}_{3}$ 에 비하여 더 높거나 근사한 함량의 중금속을 토양으로부터 추출하였다. 같은 족에 속해 지구화학적으 로 거동이 유사한 $\mathrm{Cd}$ 와 $\mathrm{Zn}$ 이 유기산 추출제와 반응하여 높은 함량이 용출되는 것이 특징적이었다.

왕수 추출과 비교하였을 때 각 단일용출법이 어느 정 도의 중금속을 용출할 수 있는지 파악하기 위하여, 전함 량에 대한 각 단일용출 함량의 비율을 Fig. 2에 표시하였다.

단일용출법은 토양 내에서 이동성이 높은 중금속 함량 을 측정하는데 이용되며, 용출 메커니즘에 따라 그 목적 이 달라진다. 일반적으로 $\mathrm{CaCl}_{2}$ 와 같은 용출제는 이온교 환에 의해 중금속을 추출하므로 토양 내 약하게 흡착된 중금속의 함량을 정량하는데 사용된다(Kabata-Pendias, 1993). 토양 내 수산화물 및 탄산염 형태의 화합물을 용 해하는데 주로 사용되는 HOAc는 토양 근권(rhizosphere) 
Table 1. Sample number, mean, median, standard deviation, and range of $\mathrm{pH}$, cation exchange capacity, organic matters, and the studied elements extracted with aqua regia and $0.01 \mathrm{M} \mathrm{CaCl}_{2}, 0.11 \mathrm{M} \mathrm{HOAc}, 0.5 \mathrm{M} \mathrm{HNO}_{3}$, and $0.005 \mathrm{M} \mathrm{DTPA}+0.01 \mathrm{M} \mathrm{CaCl}_{2}+0.1 \mathrm{M} \mathrm{TEA}$

\begin{tabular}{|c|c|c|c|c|c|c|}
\hline & & Sample number & Mean & Median & Standard deviation & Range \\
\hline & $\mathrm{pH}$ & 69 & 6.5 & 6.3 & 0.9 & $4.8 \sim 8.6$ \\
\hline Cation exc & capacity (meq/100 g) & 69 & 20.0 & 18.8 & 7.4 & $6.0 \sim 40.2$ \\
\hline & matters $(\%)$ & 69 & 4.2 & 3.5 & 2.6 & $1.0 \sim 15.0$ \\
\hline \multirow{5}{*}{$\mathrm{Cd}(\mathrm{mg} / \mathrm{kg})$} & Aqua regia & 50 & 1.3 & 1.2 & 0.5 & $0.7 \sim 2.9$ \\
\hline & $0.01 \mathrm{M} \mathrm{CaCl}_{2}$ & 50 & 0.2 & 0.2 & 0.0 & $0.1 \sim 0.3$ \\
\hline & $0.11 \mathrm{M} \mathrm{HOAc}$ & 50 & 0.7 & 0.7 & 0.1 & $0.5 \sim 1.0$ \\
\hline & $0.5 \mathrm{M} \mathrm{HNO}_{3}$ & 45 & 0.4 & 0.3 & 0.3 & $0.2 \sim 1.3$ \\
\hline & DTPA $^{*}$ & 50 & 0.3 & 0.3 & 0.1 & $0.2 \sim 1.0$ \\
\hline \multirow{5}{*}{$\mathrm{Cr}(\mathrm{mg} / \mathrm{kg})$} & Aqua regia & 69 & 72.2 & 51.7 & 58.3 & $22.3 \sim 259.6$ \\
\hline & $0.01 \mathrm{M} \mathrm{CaCl}_{2}$ & 0 & \multicolumn{4}{|c|}{ n.d. } \\
\hline & $0.11 \mathrm{M} \mathrm{HOAc}$ & 0 & \multicolumn{4}{|c|}{ n.d. } \\
\hline & $0.5 \mathrm{M} \mathrm{HNO}_{3}$ & 66 & 1.7 & 1.4 & 1.5 & $0.0 \sim 7.3$ \\
\hline & DTPA & 53 & 0.2 & 0.2 & 0.1 & $0.1 \sim 0.5$ \\
\hline \multirow{5}{*}{$\mathrm{Cu}(\mathrm{mg} / \mathrm{kg})$} & Aqua regia & 69 & 36.0 & 25.7 & 40.8 & $3.6 \sim 273.6$ \\
\hline & $0.01 \mathrm{M} \mathrm{CaCl}_{2}$ & 39 & 0.2 & 0.1 & 0.0 & $0.1 \sim 0.3$ \\
\hline & $0.11 \mathrm{M} \mathrm{HOAc}$ & 9 & 1.1 & 0.6 & 1.1 & $0.1 \sim 3.2$ \\
\hline & $0.5 \mathrm{M} \mathrm{HNO}_{3}$ & 69 & 7.9 & 7.1 & 6.4 & $1.2 \sim 43.9$ \\
\hline & DTPA & 65 & 3.4 & 2.8 & 2.6 & $0.2 \sim 13.8$ \\
\hline \multirow{5}{*}{$\mathrm{Ni}(\mathrm{mg} / \mathrm{kg})$} & Aqua regia & 69 & 43.0 & 36.4 & 22.3 & $15.1 \sim 118.8$ \\
\hline & $0.01 \mathrm{M} \mathrm{CaCl}_{2}$ & 8 & 0.1 & 0.1 & 0.1 & $0.0 \sim 0.4$ \\
\hline & $0.11 \mathrm{M} \mathrm{HOAc}$ & 1 & 0.6 & 0.6 & & 0.6 \\
\hline & $0.5 \mathrm{M} \mathrm{HNO}_{3}$ & 69 & 2.0 & 1.6 & 1.5 & $0.2 \sim 7.8$ \\
\hline & DTPA & 58 & 0.9 & 0.7 & 0.8 & $0.1 \sim 4.2$ \\
\hline \multirow{5}{*}{$\mathrm{Pb}(\mathrm{mg} / \mathrm{kg})$} & Aqua regia & 69 & 71.1 & 69.7 & 15.1 & $28.1 \sim 122.3$ \\
\hline & $0.01 \mathrm{M} \mathrm{CaCl}_{2}$ & 16 & 1.4 & 1.4 & 0.2 & $1.0 \sim 1.6$ \\
\hline & $0.11 \mathrm{M} \mathrm{HOAc}$ & 34 & 3.9 & 3.8 & 1.0 & $2.4 \sim 6.0$ \\
\hline & $0.5 \mathrm{M} \mathrm{HNO}_{3}$ & 69 & 12.5 & 11.3 & 5.5 & $4.0 \sim 33.8$ \\
\hline & DTPA & 55 & 4.1 & 3.4 & 2.3 & $1.6 \sim 11.3$ \\
\hline \multirow{5}{*}{$\mathrm{Zn}(\mathrm{mg} / \mathrm{kg})$} & Aqua regia & 68 & 119.1 & 116.9 & 43.6 & $52.7 \sim 330.9$ \\
\hline & $0.01 \mathrm{M} \mathrm{CaCl}_{2}$ & 56 & 2.7 & 2.6 & 1.2 & $1.7 \sim 9.4$ \\
\hline & $0.11 \mathrm{M} \mathrm{HOAc}$ & 28 & 21.0 & 14.4 & 13.5 & $11.1 \sim 59.8$ \\
\hline & $0.5 \mathrm{M} \mathrm{HNO}_{3}$ & 67 & 18.4 & 11.9 & 17.5 & $2.7 \sim 84.8$ \\
\hline & DTPA & 47 & 12.9 & 8.8 & 10.0 & $5.3 \sim 45.6$ \\
\hline
\end{tabular}

The values lower than detection limits were excluded.

DTPA* $^{*}: 0.005 \mathrm{M}$ DTPA $+0.01 \mathrm{M} \mathrm{CaCl}_{2}+0.1 \mathrm{M}$ TEA

에 다량 분포하는 저분자 유기산(low molecular weight organic acids)을 모사하므로 중금속의 생물이용도를 측정 하는데 이용되기도 한다(Meers et al., 2007b). 희석된 산 인 $\mathrm{HNO}_{3}$ 는 지구화학적으로 이동도가 높은 중금속 함량 을 확인하는 방법으로 적용되며(Tipping et al., 2003), DTPA 혼합용출은 토양 뿌리의 삼출물(exudates)을 모사 하여 식물이용도를 측정하는데 이용된다.

이 연구에서 $\mathrm{Cd}$ 의 경우, 전함량에 비하여 $\mathrm{HOAc}$ 에서
평균 약 $57 \%, \mathrm{HNO}_{3}$ 에서 평균 약 $31 \%$ 정도가 용출되어 토양 내 존재하는 $\mathrm{Cd}$ 가 수산화물 및 탄산염 형태로 다 량 존재하는 것으로 예상되었다(Fig. 2). $\mathrm{Cr}$ 과 $\mathrm{Ni}$ 는 단일 용출법을 적용하였을 때 왕수에 비하여 매우 적은 함량 만이 추출 $\left(\mathrm{HNO}_{3}\right.$ 를 적용하였을 때 $\mathrm{Cr} \mathrm{3 \% ,Ni} 5 \%$ 정도) 되어 채취한 토양 내에서 이들 중금속이 매우 강한 결합 형태로 존재할 것으로 판단하였다. $\mathrm{Cu}$ 는 $\mathrm{HNO}_{3}$ 를 가하 였을 때 왕수 추출에 비하여 평균 약 $30 \%$, DTPA 적용 


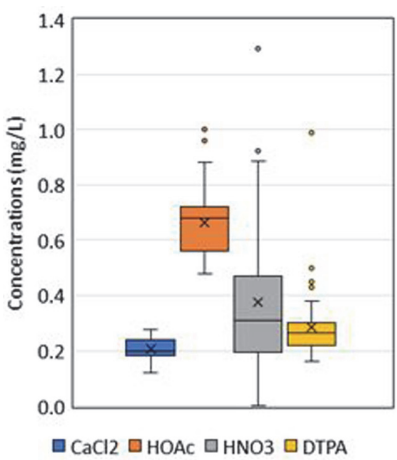

(a) $\mathrm{Cd}$

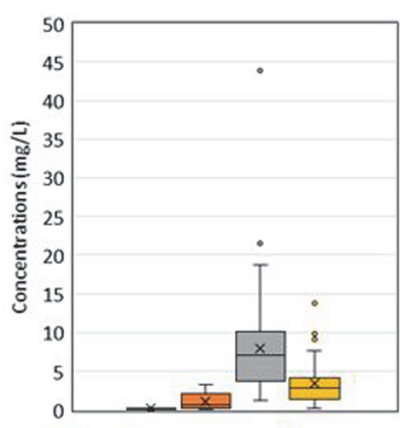

$\square \mathrm{CaCl} 2$ 口 HOAC $\square \mathrm{HNO} 3$ 口DTPA

(c) $\mathrm{Cu}$

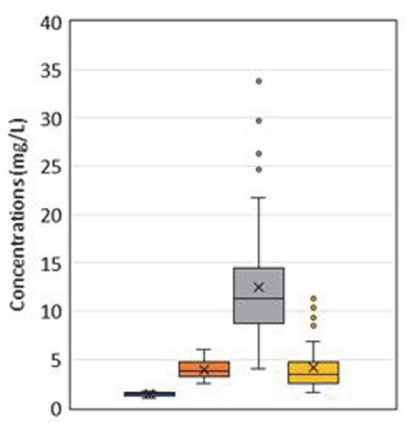

$\square \mathrm{CaCl} 2 \square \mathrm{HOAC} \square \mathrm{HNO}$ 口DTPA

(e) $\mathrm{Pb}$

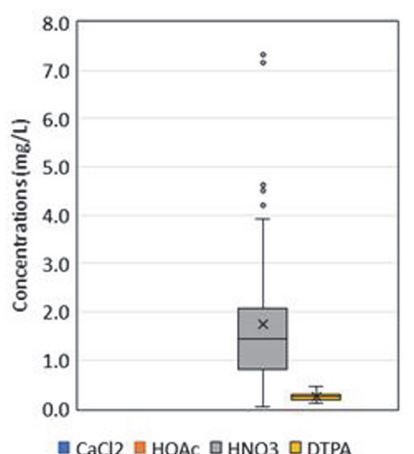

(b) $\mathrm{Cr}$

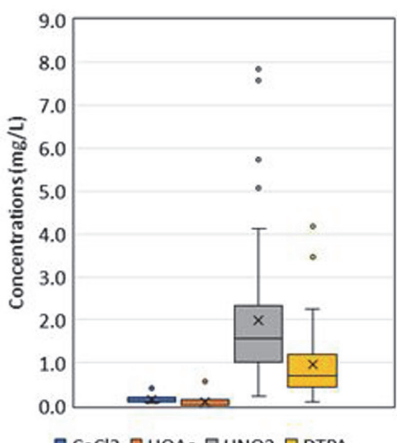

(d) $\mathrm{Ni}$

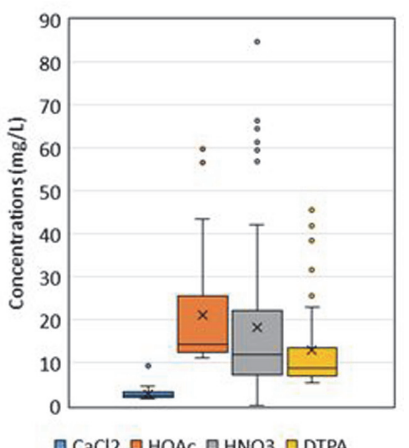

(f) $\mathrm{Zn}$

Fig. 1. Ranges of the heavy metals extracted from the soil samples with the studied single extraction methods. Refer to the text for each symbol.

시 약 $12 \%$ 정도가 용출되었다. $\mathrm{Pb}$ 는 $\mathrm{HNO}_{3}$ 적용시 약 $18 \%$ 정도, $\mathrm{Zn}$ 은 $\mathrm{HOAc}$ 적용시 약 $16 \%, \mathrm{HNO}_{3}$ 적용시 약 $14 \%$ 정도가 용출되었다.

\section{3. 통계학적 분석}

각 중금속에 대하여 왕수를 이용한 전함량 및 각 단일 용출법 결과 간의 상관관계를 파악한 후, Pearson 상관계 수가 0.6 이상 $(p<0.01)$ 되는 값들만 정리하여 Table 2 에 나타내었다. 이때, 토양의 물리화학적 성질이 단일용 출 결과에 미치는 영향을 파악하기 위하여 토양을 $\mathrm{pH}$,

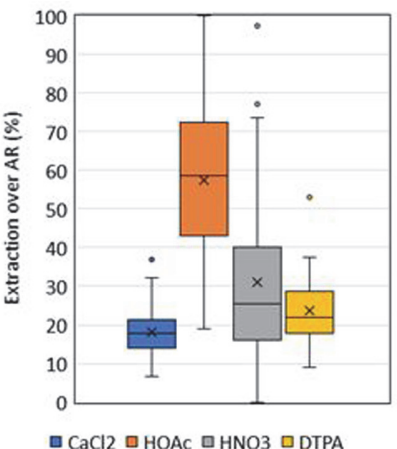

(a) $\mathrm{Cd}$

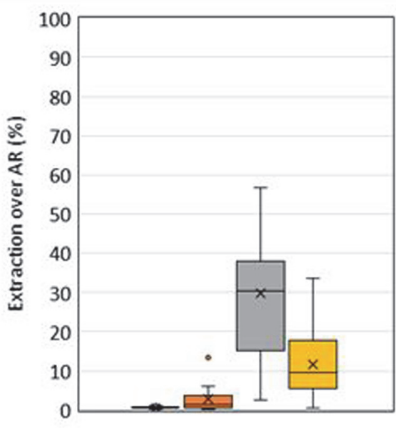

$\square \mathrm{CaCl} 2$ घ HOAC $\square$ HNO3 $\square$ DTPA

(c) $\mathrm{Cu}$

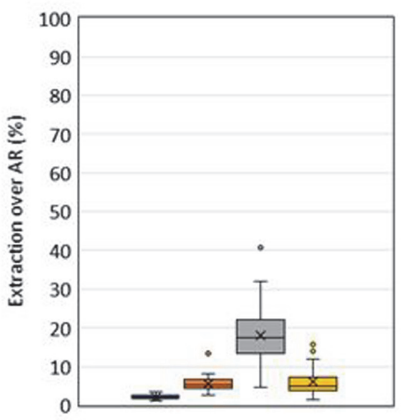

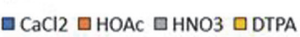

(e) $\mathrm{Pb}$

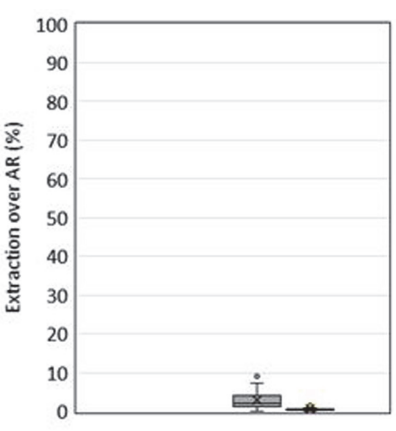

- $\mathrm{CaCl} 2=\mathrm{HOAC}$ 口HNO3 $\square$ DTPA

(b) $\mathrm{Cr}$

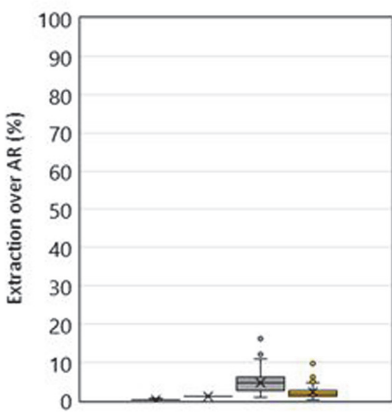

- $\mathrm{CaCl} 2$ घHOAC $\square \mathrm{HNO}$ 口DTPA

(d) $\mathrm{Ni}$

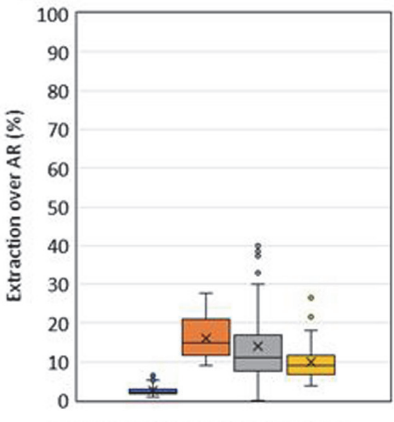

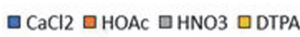

(f) $\mathrm{Zn}$
Fig. 2. Extraction ratio of the heavy metals with the studied single extraction methods over aqua regia (AR) extraction. Refer to the text for each symbol.

$\mathrm{CEC}, \mathrm{OM}$ 별로 각각 평균값 이상과 이하의 두 그룹으로 분류한 후 각 그룹 내에서 중금속 간의 상관관계를 산출 하였다.

단일용출법 가운데 DTPA 추출 결과가 다른 단일용출 및 왕수 추출 결과와 상관관계가 높은 것으로 나타났다 (Table 2). $\mathrm{Cd}$ 의 경우, $\mathrm{DTPA}$ 추출 결과는 낮은 $\mathrm{pH}(<6.6)$ 토양을 왕수로 추출한 결과, 높은 $\mathrm{CEC}(>20.0 \mathrm{meq} / 100 \mathrm{~g})$ 를 갖는 토양을 $\mathrm{HNO}_{3}$ 로 추출한 결과, 높은 $\mathrm{OM}(>0.6 \%)$ 토양을 $\mathrm{HNO}_{3}$ 추출한 결과와 0.6 이상의 상관계수를 보 였다. 이러한 결과는 토양을 $\mathrm{pH}, \mathrm{CEC}, \mathrm{OM}$ 에 따라 구분 
Table 2. Pearson correlation coefficients higher than 0.6 among pseudo-total and each single extraction method

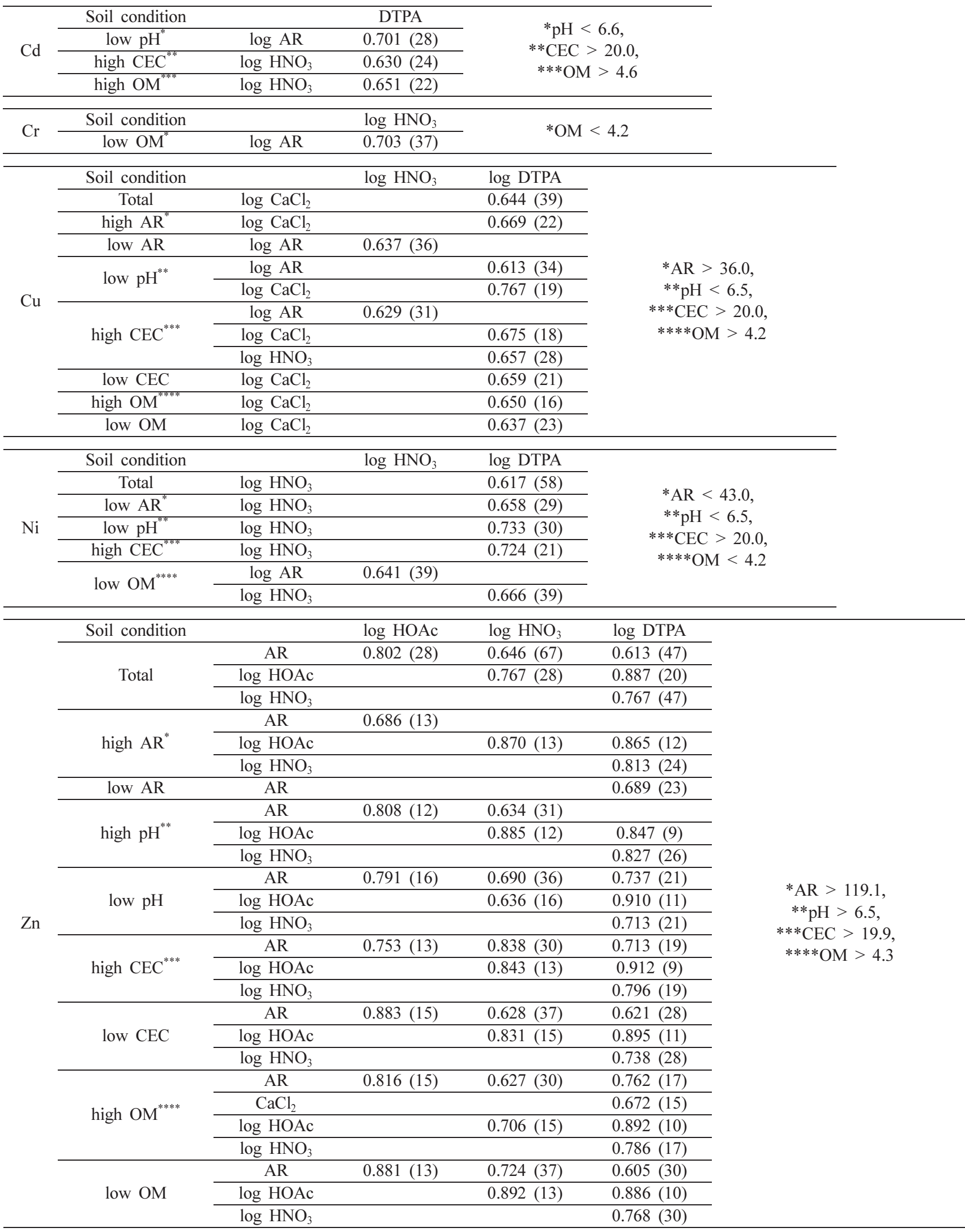

For $\mathrm{Pb}$, no Pearson correlation coefficient higher than 0.6 existed. The numbers in brackets represent the number of samples. CEC: cation exchange capacity (meq/100 g), OM: organic matter content $(\%)$, AR: aqua regia extraction $(\mathrm{mg} / \mathrm{kg})$ 
하지 않고 한꺼번에 통계분석에 투입하였을 때에는 나타 나지 않는 결과로서, 토양의 물리화학적 특성이 단일용 출의 결과에 일정 부분 영향을 미칠 수 있는 가능성을 나타낸다.

$\mathrm{Cr}$ 은 전체적으로 용출법 사이의 상관관계가 불량하여, 낮은 $\mathrm{OM}$ 토양을 $\mathrm{HNO}_{3}$ 로 용출한 경우에만 토양 내 전 함량과 0.703 의 상관계수를 보였다. 이는 아마도 $\mathrm{Cr}$ 이 채 취한 토양 내에서 대부분 강한 결합 형태로 존재하였기 때문으로, 이 연구에서 사용한 단일용출법 중 가장 강력 한 용출제인 $\mathrm{HNO}_{3}$ 에 의하여 $\mathrm{Cr}$ 이 다량 용출되어 전함 량과 상관성이 높게 나타난 것으로 생각한다. $\mathrm{Cu}$ 는 모두 11 쌍의 용출법 간에서 좋은 상관관계를 보였으며 다른 중금속에서는 나타나지 않는 $\mathrm{CaCl}_{2}$-DTPA간의 높은 상관 관계를 보이는 것이 특징적이었다. 이는 희석된 염 $\left(\mathrm{CaCl}_{2}\right)$ 에 의해서도 용이하게 추출될 정도로 토양 입자와 약하 게 결합하고 있는 $\mathrm{Cu}$ 가 $\mathrm{DTPA}$ 에 의해서도 선택적으로 추출될 수 있음을 말한다. 높은 $\mathrm{CEC}$ 를 갖는 토양은 왕 수- $\mathrm{HNO}_{3}, \mathrm{CaCl}_{2}$-DTPA, $\mathrm{HNO}_{3}$-DTPA 간에 높은 상관관 계를 보였으며, 특히 토양을 물리화학적 특성별로 구분 하지 않고 전체를 대상으로 하였을 경우에도 $\mathrm{CaCl}_{2}$ 와 $\mathrm{DTPA}$ 추출 결과 사이에는 0.644 의 양호한 상관계수를 보였다. $\mathrm{Ni}$ 는 6 쌍의 용출법 간에 0.6 이상의 상관계수를 나타내었으며, 이는 대부분 $\mathrm{HNO}_{3}$-DTPA 간의 상관관계 에서 나타났다. $\mathrm{Pb}$ 는 용출법 간에 0.6 이상의 상관계수 를 보인 경우가 전혀 없었다.

가장 특기할 만한 것은 $\mathrm{Zn}$ 의 경우로서, 두 용출법 간 의 상관계수가 0.6 이상인 경우가 47개로 다른 중금속에 비하여 매우 많은 것으로 드러났으며, 상관계수가 0.8 이 상인 항목도 21개나 되었다(Table 2). 특히 $\mathrm{CaCl}_{2}$ 를 제외 한 다른 단일용출법에 의한 $\mathrm{Zn}$ 추출 함량과 왕수 추출에 의한 $\mathrm{Zn}$ 전함량 상호 간에 좋은 상관관계를 보였다. $\mathrm{pH}$, $\mathrm{CEC}, \mathrm{OM}$ 별로 구분하지 않은 전체 토양을 대상으로 한 경우에도, 전함량과 $\mathrm{HOAc}, \mathrm{HNO}_{3}, \mathrm{DTPA}$ 추출량 간에 모 두 높은 상관계수를 나타내었다. 이처럼 전체 토양을 대 상으로 하였을 때 모든 추출제 간에 좋은 상관관계를 보 인 것은 다른 중금속에서는 나타나지 않은 결과이다. 이 러한 모든 추출제 간 높은 상관관계는 낮은 $\mathrm{pH}$ 토양, 높 거나 낮은 $\mathrm{CEC}$ 토양, 높거나 낮은 $\mathrm{OM}$ 토양에서도 나타 났다. 다른 중금속과 달리 $\mathrm{Zn}$ 이 모든 추출제 간에 높은 상관성을 보인 물리적 또는 화학적 원인은 규명할 수 없 으나, 토양 조건을 불문하고 무기염, 유기산, 무기산, 혼 합추출제, 왕수의 $\mathrm{Zn}$ 용출 정도가 비례하는 것은 흥미로 운 사실이다. 다른 중금속에서 전함량과 0.6 이상의 상관 계수를 보인 용출법은, 낮은 $\mathrm{pH}$ 토양을 DTPA로 용출한
$\mathrm{Cd}$, 낮은 $\mathrm{OM}$ 토양을 $\mathrm{HNO}_{3}$ 로 추출한 $\mathrm{Cr}$, 낮은 전함량 토양을 $\mathrm{HNO}_{3}$ 로 추출한 $\mathrm{Cu}$, 낮은 $\mathrm{pH}$ 토양을 $\mathrm{DTPA}$ 로 추 출한 $\mathrm{Cu}$, 높은 $\mathrm{CEC}$ 토양을 $\mathrm{HNO}_{3}$ 로 추출한 $\mathrm{Cu}$, 낮은 $\mathrm{OM}$ 토양을 $\mathrm{HNO}_{3}$ 로 추출한 $\mathrm{Ni}$ 정도였다.

각 단일용출 결과의 분산을 토양의 물리화학적 특성 및 중금속 전함량으로 나타낼 수 있는지를 파악하기 위하여 다중회귀분석을 수행하였다(Table 3). 이때 토양은 높은 $\mathrm{pH}$, 낮은 $\mathrm{pH}$, 전체 $\mathrm{pH}$ 토양의 세 그룹으로 구분하였으 며, 종속변수는 각 단일용출 결과값, 독립변수는 $\mathrm{pH}, \mathrm{CEC}$, $\mathrm{OM}$ 및 전함량으로 하였다. 다중회귀분석은 독립변수의 동시(enter) 투입방식 및 단계(stepwise) 투입방식을 모두 수행하였다. 동시투입방식은 모든 독립변수를 포함하여 분석하는 것이며, 단계투입방식은 종속변수에 영향력이 있는 변수들만을 회귀식에 포함시키는 것이다. Table 3은 결정계수(coefficient of determination, $\mathrm{R}^{2}$ )가 0.4 이상이고 매우 낮은 $p$ 값을 갖는 회귀식만 기술한 것이다. 이 회귀 식들은 (1) 토양의 $\mathrm{pH}, \mathrm{CEC}, \mathrm{OM}$ 및 중금속 전함량(독립 변수)으로부터 단일용출 결과(종속변수)를 수학적으로 추 정할 수 있는 것과 (2) 독립변수의 단계별 투입방식에 의 해 도출된 회귀식의 경우, 토양의 물리화학적 특성과 전 함량 중 단일용출 결과에 중요한 영향을 미치는 것을 추 정할 수 있다는 기능이 있다.

$\mathrm{Cd}, \mathrm{Cu}, \mathrm{Ni}$ 는 낮은 $\mathrm{pH}$ 를 갖는 토양에 대해서만 0.4 이 상의 결정계수를 갖는 회귀식이 도출되었다(Table 3). 예 를 들어, $\mathrm{Cd}$ 의 경우, 낮은 $\mathrm{pH}$ 토양에 대한 $\mathrm{DTPA}$ 용출 결과는 변수 동시투입방식에서 $\mathrm{DTPA}=0.053 \mathrm{pH}-0.001$ $\mathrm{CEC}-0.130 \log \mathrm{OM}+0.858 \log \mathrm{AR}-0.003$ 회귀식으로 표현될 수 있으며 이 식은 DTPA 분산의 $56 \%\left(\mathrm{R}^{2}\right)$ 를 설 명할 수 있음을 나타낸다. 한편, 동일한 독립변수를 이용 하여 단계별 투입방식을 수행한 결과, DTPA $=0.882$ $\log \mathrm{AR}+0.205$ 회귀식이 산출되었으며 이는 DTPA 분산 의 $49 \%$ 를 설명할 수 있다. 즉 낮은 $\mathrm{pH}$ 토양을 DTPA로 추출할 때 그 결과는 $\mathrm{Cd}$ 전함량만으로도 약 $49 \%$ 정도가 설명될 수 있음을 나타낸다. 이는 모든 독립변수 $(\mathrm{pH}, \mathrm{CEC}$, $\mathrm{OM}$, 전함량)를 투입할 경우 $(56 \%)$ 에 비해서 약 $7 \%$ 의 설 명력이 감소하나, 왕수 추출 결과(AR)만으로도 비슷한 정도의 분산을 설명할 수 있다는 의미이다. $\mathrm{Cu}$ 와 $\mathrm{Ni}$ 의 경우, 낮은 $\mathrm{pH}$ 토양을 $\mathrm{DTPA}$ 또는 $\mathrm{HNO}_{3}$ 로 추출할 때의 예상 결과값을 나타내는 회귀식이 각각 도출되었으며 $\left(\mathrm{R}^{2}\right.$ $\fallingdotseq 40 \%$, 이때 회귀식에는 모든 독립변수가 필요한 것으 로 나타났다. $\mathrm{Cr}$ 과 $\mathrm{Pb}$ 는 0.4 이상의 $\mathrm{R}^{2}$ 값을 갖는 회귀 식이 도출되지 않았다.

$\mathrm{Zn}$ 의 경우에는 모든 $\mathrm{pH}$, 높은 $\mathrm{pH}$, 낮은 $\mathrm{pH}$ 조건에서 모두 0.4 이상의 결정계수를 갖는 회귀식이 18 개나 도출 
Table 3. The results of multiple regression analyses for each heavy metal

\begin{tabular}{|c|c|c|c|c|c|}
\hline Metals & Soil condition & Variable input & Multiple regression analysis & $\mathrm{R}^{2}$ & $p$ value \\
\hline \multirow[t]{2}{*}{$\mathrm{Cd}$} & \multirow[t]{2}{*}{ low $\mathrm{pH}$} & enter & $\begin{array}{l}\text { DTPA }=0.053 \mathrm{pH}-0.001 \mathrm{CEC}- \\
0.130 \log \mathrm{OM}+0.858 \log \mathrm{AR}-0.003\end{array}$ & 0.561 & 0.001 \\
\hline & & stepwise & $\mathrm{DTPA}=0.882 \log \mathrm{AR}+0.205$ & 0.491 & $<0.001$ \\
\hline $\mathrm{Cu}$ & low $\mathrm{pH}$ & enter & $\begin{array}{c}\log \mathrm{DTPA}=0.183 \mathrm{pH}+0.003 \mathrm{CEC}- \\
0.023 \log \mathrm{OM}+0.739 \log \mathrm{AR}-1.812\end{array}$ & 0.413 & 0.003 \\
\hline $\mathrm{Ni}$ & low $\mathrm{pH}$ & enter & $\begin{array}{c}\log \mathrm{HNO}_{3}=0.262 \mathrm{pH}+0.005 \mathrm{CEC} \\
-0.190 \log \mathrm{OM}+0.886 \log \mathrm{AR}-2.711\end{array}$ & 0.404 & 0.001 \\
\hline \multirow{18}{*}{$\mathrm{Zn}$} & \multirow{6}{*}{ all $\mathrm{pH}$} & enter & $\begin{array}{c}\operatorname{logHOAc}=-0.015 \mathrm{pH}-0.001 \mathrm{CEC}+ \\
0.003 \log \mathrm{OM}+0.003 \mathrm{AR}+0.935\end{array}$ & 0.648 & $<0.001$ \\
\hline & & stepwise & $\operatorname{logHOAc}=0.003 \mathrm{AR}+0.835$ & 0.643 & $<0.001$ \\
\hline & & enter & $\begin{array}{c}\log \mathrm{HNO}_{3}=-0.022 \mathrm{pH}+0.012 \mathrm{CEC}+ \\
0.317 \log \mathrm{OM}+0.005 \mathrm{AR}+0.224\end{array}$ & 0.554 & $<0.001$ \\
\hline & & stepwise & $\begin{array}{c}\log \mathrm{HNO}_{3}=0.005 \mathrm{AR}+0.012 \mathrm{CEC}+ \\
0.314 \operatorname{logOM}+0.101\end{array}$ & 0.55 & $<0.001$ \\
\hline & & enter & $\begin{array}{c}\log \mathrm{DTPA}=-0.015 \mathrm{pH}+0.010 \mathrm{CEC}+ \\
0.168 \log \mathrm{OM}+0.003 \mathrm{AR}+0.419\end{array}$ & 0.478 & $<0.001$ \\
\hline & & stepwise & $\log \mathrm{DTPA}=0.003 \mathrm{AR}+0.010 \mathrm{CEC}+0.398$ & 0.459 & $<0.001$ \\
\hline & \multirow{6}{*}{ high $\mathrm{pH}$} & stepwise & $\mathrm{CaCl}_{2}=0.058 \mathrm{CEC}-0.962 \log \mathrm{OM}+2.025$ & 0.487 & $<0.001$ \\
\hline & & stepwise & $\log \mathrm{HOAc}=0.003 \mathrm{AR}+0.868$ & 0.652 & 0.001 \\
\hline & & enter & $\begin{array}{c}\log \mathrm{HNO}_{3}=0.045 \mathrm{pH}+0.018 \mathrm{CEC}+ \\
0.206 \log \mathrm{OM}+0.005 \mathrm{AR}-0.357\end{array}$ & 0.631 & $<0.001$ \\
\hline & & stepwise & $\log \mathrm{HNO}_{3}=0.005 \mathrm{AR}+0.019 \mathrm{CEC}+0.048$ & 0.593 & $<0.001$ \\
\hline & & enter & $\begin{array}{c}\log \mathrm{DTPA}=0.046 \mathrm{pH}+0.016 \mathrm{CEC}- \\
0.144 \log \mathrm{OM}+0.004 \mathrm{AR}-0.076\end{array}$ & 0.525 & 0.003 \\
\hline & & stepwise & $\log \mathrm{DTPA}=0.004 \mathrm{AR}+0.015 \mathrm{CEC}+0.237$ & 0.508 & $<0.001$ \\
\hline & \multirow{6}{*}{ low $\mathrm{pH}$} & enter & $\begin{array}{c}\log \mathrm{HOAc}=0.046 \mathrm{pH}-0.014 \mathrm{CEC}+ \\
0.034 \log \mathrm{OM}+0.005 \mathrm{AR}+0.669\end{array}$ & 0.748 & 0.003 \\
\hline & & stepwise & $\log \mathrm{HOAc}=0.004 \mathrm{AR}-0.014 \mathrm{CEC}+0.955$ & 0.737 & $<0.001$ \\
\hline & & enter & $\begin{array}{c}\log \mathrm{HNO}_{3}=0.124 \mathrm{pH}+0.007 \mathrm{CEC}+ \\
0.367 \log \mathrm{OM}+0.006 \mathrm{AR}-0.623\end{array}$ & 0.591 & $<0.001$ \\
\hline & & stepwise & $\begin{array}{c}\log \mathrm{HNO}_{3}=0.006 \mathrm{AR}+0.369 \log \mathrm{OM}+ \\
0.224\end{array}$ & 0.55 & $<0.001$ \\
\hline & & enter & $\begin{array}{c}\log \mathrm{DTPA}=-0.025 \mathrm{pH}-0.001 \mathrm{CEC}+ \\
0.216 \log \mathrm{OM}+0.004 \mathrm{AR}+0.550\end{array}$ & 0.584 & 0.005 \\
\hline & & stepwise & $\log \mathrm{DTPA}=0.004 \mathrm{AR}+0.478$ & 0.543 & $<0.001$ \\
\hline
\end{tabular}

되었다(Table 3). 예를 들어, 낮은 $\mathrm{pH}$ 를 갖는 토양으로부 터 $\mathrm{HOAc}$ 를 이용하여 $\mathrm{Zn}$ 을 추출하는 경우, $\log \mathrm{HOAc}=$ $0.004 \mathrm{AR}-0.014 \mathrm{CEC}+0.955$ 회귀식에 의하여, $\mathrm{Zn}$ 전 함량(AR)과 $\mathrm{CEC}$ 분석 결과만으로 $74 \%$ 에 이르는 $\mathrm{HOAc}$ 추출 결과의 분산을 예측할 수 있다. 즉 이는 토양 내 $\mathrm{Zn}$ 전함량과 $\mathrm{CEC}$ 가 $\mathrm{HOAc}$ 로 추출할 수 있는 $\mathrm{Zn}$ 함량에 지 대한 영향을 미친다는 의미이다.

$\mathrm{Zn}$ 의 경우, 단계별 회귀분석의 결과를 보았을 때, 토양 내 전함량이 다른 단일용출 함량과의 상관관계가 높았으 므로 추출제의 종류에 관계없이 모든 회귀식에 포함되는
것은 당연하다고 할 수 있다. 그러나 높은 $\mathrm{pH}$ 를 갖는 토 양 내 $\mathrm{Zn}$ 을 $\mathrm{CaCl}_{2}$ 로 추출할 경우, 전함량보다는 $\mathrm{CEC}$ 와 $\mathrm{OM}$ 이 중요한 영향을 미치는 것으로 나타난 것은 특기할 만하다. 이는 $\mathrm{CaCl}_{2}$ 처럼 희석된 무기염에 의해 용출되는 $\mathrm{Zn}$ 함량은 강한 혼합산인 왕수에 의해 추출되는 함량과 관계가 없으며 도리어 $\mathrm{CEC}$ 나 $\mathrm{OM}$ 같은 토양의 특성에 의 해 조절될 수도 있음을 의미한다. 단계별 회귀분석 결과, 전함량 이외에 $\mathrm{Zn}$ 의 추출에 영향을 미칠 수 있는 토양의 물리화학적 특성을 살펴보면, 모든 $\mathrm{pH}$ 토양의 $\mathrm{HNO}_{3}$ 추 출시 $\mathrm{CEC}$ 와 $\mathrm{OM}, \mathrm{DTPA}$ 추출시 $\mathrm{CEC}$, 높은 $\mathrm{pH}$ 토양의 
$\mathrm{HNO}_{3}$ 와 DTPA 추출시 $\mathrm{CEC}$, 낮은 $\mathrm{pH}$ 토양의 $\mathrm{HOAc}$ 추 출시 $\mathrm{CEC}, \mathrm{HNO}_{3}$ 추출시 $\mathrm{OM}$ 이 영향을 미치는 것으로 나타났다.

\section{4. 결 론}

중금속으로 오염된 토양을 조사할 경우, 일반적으로 $\mathrm{pH}, \mathrm{CEC}, \mathrm{OM}$ 및 왕수를 이용한 전함량 분석은 기본적 으로 수행하게 된다. 이 연구에서는 토양의 기본적인 물 리화학적 분석 결과와 다양한 단일용출법의 중금속 용출 결과를 이용하여 1) $\mathrm{pH}, \mathrm{CEC}, \mathrm{OM}$ 으로 분류한 토양 표 본에서 전함량 분석법을 포함한 단일용출법 결과 간의 상관분석, 2) 단일용출법에 의해 추출되는 중금속 함량과 토양 내 존재하는 중금속의 전함량 및 토양의 물리화학 적 특성 간의 회귀분석을 통한 상호 통계적 관련성 분석 을 수행하였다.

이 연구에서 $\mathrm{pH}, \mathrm{CEC}, \mathrm{OM}$ 의 크기별로 토양을 분류하 여 통계분석을 수행한 결과, 분류하지 않은 전체 토양을 대상으로 한 결과와는 큰 차이를 보였으며, 이는 토양의 물리화학적 특성이 단일용출 결과에 영향을 미칠 수 있 음을 직접적으로 나타낸 것이다. 또한, 단일용출법에 의 해 용출되는 $\mathrm{Zn}$ 함량은 전함량뿐만 아니라 $\mathrm{pH}, \mathrm{CEC}, \mathrm{OM}$ 등 토양의 물리화학적 특성에 의해서도 큰 영향을 받음 이 회귀분석 결과를 통하여 나타났다.

국제적으로 토양 내 존재하는 중금속의 이동도 또는 오 염도를 평가하기 위하여 단일용출법이 널리 이용되고 있 다. 토양의 물리화학적 특성 및 대상 원소의 특성에 따 라 단일용출법에 의한 결과는 상이하게 달라지지만 여전 히 다양한 중금속을 동시에 추출할 수 있다는 편의성에 기대어 단일용출법이 가장 널리 이용되고 있는 추세이다. 현재까지 단일용출법을 대체할 수 있는 기술이 개발되지 않아 앞으로도 단일용출법을 이용한 중금속의 이동도 또 는 오염도 평가가 주를 이룰 것으로 생각되므로 여전히 이에 대한 더욱 심도 깊은 연구가 필요할 것이다. 특히 이 연구에서 토양을 물리화학적 특성으로 분류한 후 회 귀분석을 수행하는 방식은 최근 다양한 학문분야에 접목 되고 있는 머신러닝 기술과 흡사하다. 비록 이 연구에서 는 추론통계적 기법만을 이용하였으나, 추후 다양한 학 자에 의하여 많은 연구결과가 확보될 시 토양의 물리화 학적 특성, 중금속 전함량, 단일용출법 간의 더욱 명확한 상호 관련성 분석이 가능할 것으로 기대된다.

\section{사 사}

이 논문은 한국연구재단 지역대학우수과학자지원사업
(과제번호 2020R1I1A307435911) 및 농촌진흥청(과제번 호 2G24015053032020)의 지원을 받아 수행하였습니다.

\section{References}

Boyle, J. (2004) A comparison of two methods for estimating the organic matter content of sediments. J. Paleolimn., v.31, p.125127. doi: 10.1023/b:jopl.0000013354.67645.df

Chiou, W.-Y. and Hsu, F.-C. (2019) Copper toxicity and prediction models of copper content in leafy vegetables. Sustainability, v.11, p.6215. doi: $10.3390 /$ su11226215

DIN (Deutsches Institut für Normung), 1997. BodenbeschaffenheitExtraktion von Spurenelementen mit Ammoniumnitratlösung (ISO 19730:2008), Germany. doi: 10.31030/1517786

Han, H.-J., Ko, M.-S., Ko, J.I., and Lee, J.-U. (2020) Study on soil extraction methods for contamination assessment of heavy metals in soil. J. Korean Soc. Miner. Energy Resour. Eng., v.57, n.5, 471-482. doi: 10.32390/ksmer.2020.57.5.471

Heemsbergen, D.A., Warne, M.S.J., Broos, K., Bell, M., Nash, D., McLaughlin, M., Whatmuff, M., Barry, G., Pritchard, D., and Penney, N. (2009) Application of phytotoxicity data to a new Australian soil quality guideline framework for biosolids. Sci. Tot. Environ., v.407, p.2546-2556. doi: 10.1016/j.scitotenv.2009. 01.016

Houba, V.J.G., Temminghoff, E.J.M., Gaikhorst, G.A., and van Vark, W. (2000) Soil analysis procedure using $0.01 \mathrm{M}$ calcium chloride as extraction reagent. Commun. Soil Sci. Plant Anal., v.31, p.1299-1396. doi: 10.1080/00103620009370514

Kabata-Pendias, A., (1993) Behavioural properties of trace metals in soils. J. Appl. Geochem., v.8, p3-9. doi: 10.1016/s0883-2927(09) 80002-4

Kelepertzis, E., Paraskevopoulou, V., Argyraki, A., Fligos, G., and Chalkiadaki, O. (2015) Evaluation of single extraction procedures for the assessment of heavy metal extractability in citrus agricultural soil of a typical Mediterranean environment (Argolida, Greece). J. Soils Sediments, v.15, p.2265-2275. doi: 10.1007/ s11368-015-1163-x

Kim, G.H., Kim, G.Y., Kim, J.K., S, D.M., Seo, J.S., Son, B.K., Yang, J.E., Um, K.C., Lee, S.E., Jeong, K.Y., Jeong, D.Y., Jeong, Y.T., Jeong, J.B., and Hyeon, H.N. (2009) Soil science, 2nd Ed. Hyangmoon-sa, Seoul, Korea, 195p.

Krishnamurti, G.S.R. and Naidu, R. (2003) Solid-solution equilibria of cadmium in soils. Geoderma, v.113, p.17-30. doi: 10.1016/ s0016-7061(02)00313-0

Lim, G.H., Kim, K.H., Seo, B.H., and Kim, K.R. (2014) Transfer function for phytoavailable heavy metals in contaminated agricultural soil. Korean J. Environ. Agric., v.33, p.271-281. doi: 10.5338/kjea.2014.33.4.271

Lima, E.S.A., Sobrinho, N.M.B,A., Pérez, D.V., and Coutinho, I.B. (2016) Comparing methods for extracting heavy metals from histosols for establishing quality reference values. Rev. Bras. Ciênc. Solo, v.40, e0150097. doi: 10.1590/18069657rbcs20150097

Lindsay, W.L. and Norvell, W.A. (1978) Development of a DTPA soil test for zinc, iron, manganese, and copper. Soil Sci. Soc. Am. 
J., v.42, p.421-428. doi: 10.2136/sssaj1978.03615995004200030009x

Lo, I.M.C. and Yang, X.Y. (1999) EDTA extraction of heavy metals from different soil fractions and synthetic soils. Water Air Soil Pollut., v.109, p.219-236. doi: 10.1023/A:1005000520321

Meers, E., Laing, G.D., Unamuno, V., Ruttens, A., Vangronsveld, J., Tack, F.M.G., and Verloo, M.G. (2007a) Comparison of cadmium extractability from soils by commonly used single extraction protocols. Geoderma, v.141, p.247-259. doi: 10.1016/j.geoderma. 2007.06.002

Meers, E., Samson, R., Tack, F.M.G., Ruttens, A., Vandegehuchte, M., Vangronsveld, J., and Verloo, M.G. (2007b) Phytoavailability assessment of heavy metals in soils by single extractions and accumulation by Phaseolus vulgaris. Environ. Exp. Bot., v.60, p.385-396. doi: 10.1016/j.envexpbot.2006.12.010

Ministry of Environment (MOE) (2020) Report on soil measurement network and soil contamination actual condition in 2019. 2021.01.15, http://webbook.me.go.kr/DLi-File/091/027/003/5671217. pdf.

Rauret, G., Lopez-Sanchez, J.F., Sahuquillo, A., Rubio, R., Davidson, C., Ure, A., and Quevauviller, Ph. (1999) Improvement of the BCR three step sequential extraction procedure prior to the certification of new sediment and soil reference materials. J. Environ. Monit., v.1, p.57-61. doi: 10.1039/a807854h

Roh, A.S., Park, J.S., Kim, Y.H., and Kang, S.S. (2015) Status and changes in chemical properties of paddy soil in Gyeonggi Province. Korean J. Soil. Sci. Fert., v.48, p.436-441. doi: 10.7745/ kjssf.2015.48.5.436

Salazar, M.J., Rodriguez, J.H., Nieto, G.L., and Pignata, M.L. (2012) Effects of heavy metal concentrations $(\mathrm{Cd}, \mathrm{Zn}$ and $\mathrm{Pb})$ in agricultural soils near different emission sources on quality, accumulation and food safety in soybean [Glycine max (L.) Merrill]. J. Hazard. Mater., v.233-234, p.244-253. doi: 10.1016/ j.jhazmat.2012.07.026

Seo, B.-H., Lim, G.-H., Kim, K.-H., Kim, J.-E., Hur, J.-H., Kim, W.I., and Kim, K.-R. (2013) Comparison of single extractions from evaluation of heavy metals phytoavailability in soil. Korean J. Environ. Agric., v.32, p.171-178. doi: 10.5338/kjea.2013.32.3.171

Song, C.-W., Han, H.-J., and Lee, J.-U. (2019) Investigation on geochemical characteristics of heavy metals in soils in the vicinity of Samcheonpo and Hadong coal-fired power plants in Korea. Econ. Environ. Geol, v.52, p.141-158. doi: 10.9719/ EEG.2019.52.2.141

Sungur, A., Soylak, M., and Ozcan, H. (2014) Investigation of heavy metal mobility and availability by the BCR sequential extraction procedure: relationship between soil properties and heavy metals availability. Chem. Spec. Bioavailab., v.26, p.219230. doi: 10.3184/095422914x14147781158674

Tessier, A., Campbell, P.G.C., and Bisson, M. (1979) Sequential extraction procedure for the speciation of particulate trace metals. Anal. Chem., v.51, p.844-851. doi: 10.1021/ac50043a017

Tipping, E., Pieuwerts, J., Pan, G., Ashmore, M.R., Lofts, S., Hill, M.T.R., Farago, M.E., and Thornton, I. (2003) The solid-solution partitioning of heavy metals $(\mathrm{Cu}, \mathrm{Zn}, \mathrm{Cd}, \mathrm{Pb})$ in upland soils of England and Wales. Environ. Pollut., v.125, p.213-225. doi: 10.1016/s0269-7491(03)00058-7

van Ranst, E., Verloo, M., Demeyer, A., and Pauwels, J.M. (1999) Manual for the soil chemistry and fertility laboratory. University of Gent, Belgium.

VSBo, 1986. Verordnung über Schadstoffhegalt im Boden, Swiss ordinance on pollutants in soils. Nr. 814.12, Publ. Eidg. Drucksachen und Materialzentrale (EDMZ), 3000 Bern, Switzerland.

Zhang, M.K., Liu, Z.Y., and Wang, H. (2010) Use of single extraction methods to predict bioavailability of heavy metals in polluted soils to rice. Commun. Soil Sci. Plant Anal., v.41, p.820-831. doi: 10.1080/00103621003592341

Zhu, Q.H., Huang, D.Y., Liu, S.L., Luo, Z.C., Zhu, H.H., Zhou, B., Lei, M., Rao, Z.X., and Cao, X.L. (2012) Assessment of single extraction methods for evaluating the immobilization effect of amendments on cadmium in contaminated acidic paddy soil. Plant Soil Environ., v.58, p.98-103. doi: 10.17221/358/2011-pse

Zimmerman, A.J. and Weindorf, D.C. (2010) Heavy metal and trace metal analysis in soil by sequential extraction: a review of procedure. Int. J. Anal. Chem., v.2010, p.1-7. doi: 10.1155/2010/ 387803 